\title{
Satın Alma Gücü Paritesi Hipotezi (SAGP)'nin OECD Ülkeleri İçin Test Edilmesi
}

\author{
Reşat CEYLAN
}

Hakan ULUCAN

rceylan@pau.edu.tr

hulucan@pau.edu.tr

\section{Testing Purchasing Power Parity Hypothesis (PPP) for OECD Countries}

\begin{abstract}
The main aim of this study is to test the validity of purchasing power parity (PPP) hypothesis for OECD countries among which the economic integration have been increasing over time. In this study purchasing power parity is tested for 25 OECD countries by using the yearly data from 1970 to 2013. KSS and AESTAR test procedures that are based on non-linear techniques are used in the study. Findings suggest that AESTAR estimation gives more robust results than KSS. Because according to AESTAR procedure the PPP hypothesis holds 20 OECD countries.

Keywords

: Purchasing Power Parity Hypothesis, Real Exchange Rate, KSS Test, AESTAR Test.

JEL Classification Codes $\quad$ : E61, F31, F41.

Özet

$\mathrm{Bu}$ çalışmanın temel amacı, aralarındaki ekonomik bütünleşmenin giderek arttığ $\mathrm{OECD}$ ülkelerinde satın alma gücü paritesi (SAGP) hipotezinin geçerliliğini test etmektir. SAGP hipotezi, reel döviz kurunun kendi ortalamasına dönme eğiliminde olacağını ifade etmektedir. Bu çalışmada 25 OECD ülkesi için SAGP hipotezi 1970-2013 dönemine ait yıllık veriler kullanılarak analiz edilmektedir. Çalışmada doğrusal olmayan zaman serisi tekniğine dayanan KSS ve AESTAR test prosedürleri kullanılmaktadır. Elde edilen bulgular, AESTAR sürecinin KSS sürecinden daha güçlü kanıtlar sunduğunu göstermekte ve 25 OECD ülkesinden 20 tanesinde SAGP'nin geçerli olduğunu ortaya koymaktadır.
\end{abstract}


Reşat CEYLAN \& Hakan ULUCAN 


\section{Giriş}

Nelson ve Plosser (1982), makroekonomik değişkenlerin -örneğin, tüketim, yatırım, GSYİH, döviz kurları gibi- önemli bir kısmının durağan olmadığını ve iktisat politikalarında ortaya çıkan yapısal değiş̧ikliklerin ya da ekonomilerde oluşan içsel ve dışsal şokların bu değişkenleri etkileyebileceğini ileri sürmüştür. Dünya ekonomisinin 1970'li yıllardan sonra girdiği yapısal dönüşümle birlikte, sermaye hareketleri serbestleşmiş, enerji fiyatlarında önemli dalgalanmalar oluşmuş ve ülke ekonomileri çeşitli şoklara maruz kalmıştır. Oluşan şoklara karşı ekonomiler, özellikle para politikalarında kurala dayalı anlayışı benimsemek zorunda kalmıştır. Kurala dayalı politika anlayışının temelinde merkez bankalarının para politikası bağlamında bağımsız olmaları düşüncesi yatmaktadır. $\mathrm{Bu}$ noktada, uluslararası finansın temel taşlarından biri olan satın alma gücü paritesi (SAGP) hipotezi önem kazanmaktadır. SAGP hipotezinin geçerli olması durumunda ulusal merkez bankaları para politikasının uygulanması konusunda döviz kurunu sürdürme zorunluluğunda olmayacaktır.

SAGP, ilk defa Cassel (1918) tarafindan ele alınmıştır. Bu hipotez, iki ülke arasındaki reel döviz kurlarının uzun dönemde dengede olmasını gerektirmektedir. Bunun anlamı sabit bir mal ve hizmet sepeti için iki ülkedeki döviz kurlarının, fiyat düzeyleri oranına eşit olmasıdır (Chang ve diğ., 2012).

Uluslararası mal piyasaları arasındaki arbitraj nedeniyle, SAGP teorisinin arkasındaki temel fikir, reel döviz kurunun uzun dönemde sabit bir denge değerine yaklaşacağı şeklindedir. Bu konu ile ilgili çalışmalar hem iktisatçılar için, hem de politika yapıcılar için kritik öneme sahiptir. Özellikle durağan olmayan bir reel kur serisi, nominal döviz kuru, yurt içi fiyat düzeyi ve yurt dışı fiyat düzeyi arasında uzun dönemli bir ilişkinin olmadığını ortaya koymaktadır ve SAGP hipotezinin geçersiz olduğunu göstermektedir. Ayrıca SAGP hipotezinin geçersiz olması para politikasının etkin olmaktan çıkacağını ifade etmektedir. Çünkü politika otoritesi SAGP hipotezini geçerli kılmak için dikkatini döviz kurlarına yöneltmek zorunda kalacaktır (Snaith, 2012). Holmes ve diğ. (2012), SAGP hipotezinin politika yapıcılar açısından iki nedenle önemli olduğunu belirtmiştir. Birincisi; az gelişmiş ülkelerde ve yurt içi enflasyon oranı ile yurt dışı enflasyon oranı arasında büyük farklılıkların söz konusu olduğu ülkelerde, döviz kurunun aşırı belirli olup olmadığını ortaya koymak için kullanılmaktadır. İkincisi; döviz kuru belirleme modellerinin temelini oluşturmakta ve bu modellerde döviz kuru belirlenirken temel bir varsayım olarak ele alınmaktadır (Karoglou ve Morley, 2012). Öte yandan, SAGP sayesinde ülkeler arası rekabet farklılıkları da ortaya konmaktadır (Roos, 1981).

Taylor (2006), SAGP teorisinin geçerliliğinin 1970'li yıllarda yaygın olduğunu 1980'li yıllarda ise yaygın olmadığını ileri sürmüştür. Ancak son yıllarda yapılan çalışmalarda ise SAGP teorisinin oldukça güçlü bir şekilde desteklendiği görülmektedir (Karoglou ve Morley, 2012). Bununla birlikte hipotezin geçerliliğinin sadece kullanılan ekonometrik yöntemlere bağlı olmadığı aynı zamanda ele alınan zaman aralığının da etkili 
olduğu görülmektedir. Öte yandan, döviz kurlarının belirlenmesinin temel kritik önemi, döviz kurlarının uzun dönemde ortalamaya dönme eğiliminde olup olmaması ve SAGP hipotezinin geçerli olup olmamasından kaynaklanmaktadır (Gözgör, 2011). Çünkü SAGP, döviz kurlarının uzun dönem denge değeri için nominal çıpa olarak alınabilmekte ve reel döviz kurlarındaki kalıcılığın belirlenmesinde kullanılabilmektedir (Rogoff, 1996). Eğer reel döviz kuru yüksek derecede kalıcı ise, ekonominin reel sektörlerini etkileyen şokların, kalıcı etkiye sahip olan tercihler ve teknoloji ile ilgili olduğu söylenebilir (Telatar ve Hasanov, 2009). Öte yandan eğer reel döviz kuru düşük düzeyde kalıcı ise oluşan şokların toplam talep kaynaklı olduğu bulgusuna ulaşılabilir. Son olarak, SAGP teorisi ülkeler arasında gelir farklılıkları olup olmadığının ortaya konmasında kullanılmaktadır. Ülkeler arasında sağlıklı refah karşılaştırmasının yapılabilmesi için SAGP hipotezinin geçerli olması gerekmektedir (Sarno ve Taylor, 2002).

Çalışmanın geri kalanı aşağıdaki gibi dizayn edilmektedir. İkinci bölümde, ilgili yazın incelemesi yapılmakta, üçüncü bölümde SAGP hipotezi tanıtılmakta ve ekonometrik yöntem ele alınmaktadır. Dördüncü bölümde veri seti tanıtılmakta ve uygulama yapılmaktadır. Beşinci bölümde ise elde edilen bulgular ve politika çıkarımlarına yer verilmektedir.

\section{Literatür Özeti}

SAGP hipotezinin geçerli olup olmadığı ile ilgili olarak, literatürde birçok çalışma yapılmış ve çelişkili sonuçlara ulaşılmıştır. Çalışmanın bu bölümü, SAGP hipotezi ile ilgili yapılan çalışmaların kısa bir özetini sunmaktadır. Bu çalışmalardan bazıları SAGP lehine kanıtlar sunarken bazıları da aleyhte kanıtlar sunmaktadır.

Breitung ve Candelon (2005), Meksika ve Asya krizlerinin SAGP hipotezinin geçerliliğini ne yönde etkilediğini araştırdıkları çalışmalarında Asya ve Latin Amerika'dan geniş bir ülke grubunu ele almışlardır. Elde edilen bulgular, esnek döviz kuru sistemini benimseyen Asya ülkelerinde SAGP hipotezinin geçerli olduğunu ancak ABD Dolarını referans para birimi olarak kabul eden Güney ve Latin Amerika ülkelerinde ise SAGP hipotezinin geçerli olmadığı şeklindedir. Ayrıca krizlerin SAGP hipotezinin geçerliliğini olumsuz etkilediği vurgulanmıştır.

Payne ve diğ. (2005), geçiş ekonomilerinden biri olarak nitelendirilen Hırvatistan'da SAGP hipotezinin geçerli olup olmadığını araştırdıkları çalışmalarında, yapısal kırılmalara izin veren birim kök testlerinin piyasa ekonomisine geçiş aşamasında olan Hırvatistan'da SAGP hipotezinin geçerliliği yönünde kanıtlar sunamadığını belirtmişlerdir.

Sayyan (2005) çalışmasında, Türkiye için 1982-2004 dönemine ait aylık verileri kullanılarak SAGP hipotezinin geçerli olup olmadığını araştırmıştır. Çalışmada, vektör hata 
düzeltme modeli ve eşbütünleşme testini kullanmış ve Türkiye'de SAGP hipotezinin geçerli olduğu sonucuna ulaşmıştır.

Alba ve Papell (2005) çalışmalarında, 1976-2002 dönemine ait verileri kullanarak, 84 gelişmiş ve gelişmekte olan ülke için SAGP hipotezinin geçerliliğini incelemiştir. Aylık veriler kullanılarak, panel birim kök yaklaşımı uygulanmış ve Avrupa ile Latin Amerika'da SAGP hipotezi geçerli olurken, Afrika ve Asya'da geçersiz olduğu bulgusu elde edilmiştir.

Benassy ve diğ. (2005), G20 ülkeleri için yapmış oldukları çalışmalarında, 19802001 dönemine ait yıllık verileri kullanmışlardır. Panel birim kök ve panel eş-bütünleşme testleri uygulanarak elde edilen sonuçlar, reel döviz kurunda önemli sapmaların olduğunu ve SAGP hipotezinin geçerli olmadığını göstermiştir.

Çağlayan ve Saçaklı (2006) çalışmalarında, Türkiye ve Birleşik Krallık ülkelerini ele almışlardır. 1995-2004 dönemine ait aylık verileri kullanılmış ve birim kök testleri ile hata düzeltme modeli uygulanmıştır. Elde edilen bulgular, Türkiye ile Birleşik Krallık arasında SAGP hipotezinin geçersiz olduğunu ortaya koymuştur.

Doğanlar (2006) çalışmasında, Azerbaycan, Kazakistan ve Kırgızistan ekonomilerini 1995-2002 dönemine ait aylık verileri kullanarak incelemiştir. Analizde Engle-Granger ve Phillips-Hansen testlerini uygulamış ve ele alınan ülkelerde SAGP hipotezinin geçersiz olduğunu belirtmiştir.

Şak (2006) çalışmasında, 1996-2006 dönemine ait aylık verileri 27 OECD ülkesi için SAGP hipotezinin geçerli olup olmadığını incelemiş, panel birim kök ve panel eşbütünleşme testlerini kullanmıştır. Elde ettiği bulgular ele alınan örneklem ülkelerinde SAGP hipotezini destekler nitelikte kanıtlar sunamamıştır.

Wallace ve Shelley (2006), Fisher ve Seater yöntemini Taylor'un veri setine uygulayarak yaptıkları çalışmalarında, SAGP lehinde güçlü kanıtlara ulaşmışlar ve Fisher ve Seater test istatistiklerinin örneklem çapına ilişkin olarak bozulmalara sahip olduğunu ve daha geniş çaplı örneklemlerde sağlıklı sonuçlar ürettiğini belirtmişlerdir.

Telatar ve Hasanov (2009), Bağımsız Devletler Topluluğu ülkeleri için SAGP hipotezinin geçerliliğini incelemişlerdir. Çalışmada ele alınan ülkeler için reel döviz kurunun durağan olup olmadığı araştırılmış ve bu ülkelerin yapısal değişim sürecinden geçtikleri belirtilmiştir. Analizde hem geleneksel birim kök testleri kullanılmış ve hem de serilerde yapısal kırılmalara izin veren doğrusal olmayan birim kök testleri kullanılmıştır. Elde edilen bulgular, yapısal kırılmalara izin veren doğrusal olmayan birim kök testlerinin örneklem ülkelerinin çoğunda SAGP hipotezi lehinde sonuçlar ürettiğini ortaya koymuştur. 
Sollis (2009), reel döviz kurunun durağan olup olmadığını Asimetrik Yumuşak Geçişli Oto Regresif modele dayanan birim kök testini kullanarak Nordik ülkeleri için araştırmış ve çalışmada kullanılan yeni test tekniğinin geleneksel yöntemlere göre daha sağlıklı sonuçlar ürettiğini vurgulamıştır.

Chang ve diğ. (2011), G-7 ülkelerinde SAGP hipotezinin geçerliliğini aylık veriler kullanarak 1994-2010 dönemi için araştırmışlar ve serilerde asimetrik uyum özelliklerine izin veren eşik eş-bütünleşme yöntemini uygulamışlardır. Elde edilen bulgular Kanada hariç, diğer ülkelerde SAGP hipotezinin geçerli olduğunu göstermiş ve uyum mekanizmasının asimetrik olduğunu ortaya koymuştur.

Gözgör (2011), Türkiye'nin temel ticari ortakları arasında SAGP hipotezinin geçerliliğini araştırdığı çalışmasında, yatay kesit bağımlılık veya bağımsızlığın önemli olduğu panel birim kök testlerinin ya da homojen veya heterojen birim kök testlerinin kullanımının uygun olduğunu göstermiş ve Türkiye ile önemli ticari ortakları arasında incelenen örneklem aralığında SAGP hipotezinin geçerli olduğunu belirtmiştir.

Güloğlu ve diğg. (2011), Türkiye’nin yoğun dış ticaret yaptığı 18 ülkeyi, 19912008 dönemi ait aylık verileri dikkate alarak incelediği çalışmasında, kırılmalı panel birim kök testini kullanmış ve SAGP hipotezinin geçerli olduğu bulgusuna ulaşmıştır.

Holmes ve diğ.(2012) yapmış olduğu çalışmada, 1972-2008 dönemine ait aylık verileri incelemiş ve kırılmalı panel birim kök testini kullanmıştır. Örnekleme aldığı OECD ülkelerinden 26 tanesinde SAGP hipotezinin geçerli olduğu sonucunu ortaya koymuştur.

Yıldırım ve Yıldırım (2012) çalışmasında, 1990-2009 verileri kullanarak Türkiye ekonomisini ele almışlardır. Adı geçen yazarlar, birim kök testlerini kullanılarak, SAGP hipotezinin geçersiz olduğu bulgusuna ulaşmışlardır.

Sadoveanu ve Ghiba (2012), Orta Avrupa Ekonomileri (Macaristan, Çek Cumhuriyeti, Polonya ve Romanya) için SAGP hipotezinin geçerliliğini araştırdıkları çalışmalarında, nominal döviz kuru ile fiyat endeksleri arasındaki uzun dönemli ilişkiyi araştırmıştır. Çalışmada farklı fiyat endeksleri kullanıldığında sonuçların ülkeden ülkeye farklılaştığı bulgusuna ulaşmışlardır.

Snaith (2012), düzey ve trend kırılmalara izin veren panel birim kök testlerini kullanarak SAGP hipotezinin geçerliliğini test ettiği çalışmasında, yapısal kırılmaların varlığında reel kur üzerinde para birimlerinin ve fiyat endekslerinin etkisinin olduğunu görmüştür. Araştırma, 15 OECD ülkesi için yapılmış ve serilerdeki kırılmaların önemi vurgulanmıştır.

Karoglou ve Morley (2012), ekonomiye vuran asimetrik şokların SAGP hipotezinin geçerliliği üzerinde doğrusal olmayan etkilere sahip olup olmadığını 
araştırdıkları çalışmalarında, son dönemlerde geliştirilen ve örneklemi alt gruplara ayırmayı sağlayan ekonometrik analiz yöntemlerini kullanmışlardır. Elde edilen bulgular, SAGP hipotezinin bazı alt dönemlerde geçerli olduğunu ancak bunun da ülkelerde benimsenen döviz kuru rejimlerine bağlı olduğunu göstermiştir.

Liu ve diğ. (2012), geçiş ülkeleri için SAGP hipotezinin geçerliliğini test etmek amacıyla, doğrusal olmayan eşik birim kök testlerini kullandıkları çalışmalarında, sadece Romanya'da hipotezin geçerli olduğunu belirtmişler ve SAGP hipotezine doğru uyum sürecinin doğrusal olmayan karakteristik yapılar sergilediğini vurgulamışlardır.

Chang ve diğ. (2012), 8 ASEAN ülkesi için SAGP hipotezinin geçerliliğini araştırdıkları çalışmalarında Sollis (2009) tarafından geliştirilen AESTAR yöntemini kullanmışlar ve hipotezin geçerliliği lehinde güçlü kanıtlar bulmuşlardır.

Korkmaz ve diğ. (2013), SAGP hipotezinin geçerliliğini Azerbaycan, Kırgızistan ve Kazakistan için araştırdıkları çalışmalarında, geleneksel birim kök testleri yanında serilerde yapısal kırılmalara izin veren birim kök testlerini de kullanmışlardır. Elde ettikleri bulgulara göre; geleneksel birim kök testleri SAGP hipotezinin geçerli olmadığı yönünde kanıtlar sunarken, yapısal kırılmalara izin veren birim kök testleri SAGP hipotezinin geçerliliği yönünde kanıtlar sunmaktadır.

Yıldırım ve diğ. (2013) çalışmasında, Türkiye için 1960-2012 dönemlerini; AB15 ve G-8 ülkeleri için 1975-2012 ve OECD ülkeleri için de 1980-2012 dönemlerini incelemişlerdir. Yıllık veriler kullanılarak zaman serisi ve panel veri analizlerini yapmışlar ve elde edilen sonuçlara göre, Türkiye için SAGP hipotezi geçersiz çıkarken, AB-15 ve G8 ülkeleri için bu hipotez geçerlidir.

Sonuç olarak literatürde SAGP hipotezinin geçerliliği ile ilgili olarak çok farklı ekonometrik tekniklerin kullanıldığı ve çalışma sonuçlarının kullanılan yönteme göre farklılık gösterebildiği anlaşılmaktadır. Örneğin, "Kalyoncu ve Kalyoncu (2008), 25 OECD ekonomisi için SAGP hipotezinin geçerliliğini araştırdıkları çalışmalarında geleneksel ADF testinin başarısız sonuç verdiğini ancak heterojen panel birim kök testlerinin ise başarılı sonuç verdiğini ortaya koymuşlardır.

Literatürde reel döviz kuru serilerinin doğrusal olmadıkları yönünde yaygın bir kanıya ulaşılmaktadır. Genel olarak dünya ekonomisinin 1970'li yıllardan sonra yaşadığ1 yapısal karakteristik niteliğe sahip şoklar dikkate alındığında birçok makroekonomik zaman serisinin doğrusal olmayan davranışlar sergileyebileceği düşünülmektedir. Serilerdeki olası bu davranışlar, iktisat politikalarına yön verenler açısından önemlidir. Özellikle, fiyat istikrarı hedefinin daha öncelikli hale geldiği 1970'li yıllardan sonra bu konu daha fazla ilgi uyandırmaya başlamıştır. 


\section{SAGP Hipotezi ve Ekonometrik Model}

SAGP hipotezi "tek fiyat kanunu"nu referans olarak almaktadır. Tek fiyat kanununa göre, serbest ticaret ve tam rekabet koşulları altında ticareti yapılan mallar için yurt içi fiyat ile ulusal para birimi cinsinden yurt dış1 fiyat zaman içinde eşitlenme eğilimindedir (Sadoveanu ve Ghiba, 2012).

$$
P_{i, t}=N E R_{t} P_{i, t}^{*}, \quad i=1,2, \ldots, n
$$

Burada; $P_{i . t}, i$. malın ulusal para birimi cinsinden $t$ anındaki fiyatını, $P_{i, t}^{*}$ aynı malın yabancı para birimi cinsinden $t$ anındaki fiyatını ve $N E R_{t}$ de $t$ anındaki nominal döviz kurunu göstermektedir. Eğer tek fiyat kanunu mutlak satın alma gücü cinsinden ifade edilirse, yurt içinde ticareti yapılan tüm mallar için SAGP aşağıdaki gibi yazılabilir.

$$
\sum_{i=1}^{n} \alpha_{i} P_{i, t}=N E R_{t} \sum_{i=1}^{n} \alpha_{i} P_{i, t}^{*}
$$

Burada, $\alpha_{i}$ toplamı birime eşit olan ve fiyat endeksinde yer alan mallara verilen ağırlıkları gösteren parametredir. SAGP'den sapmaları içeren diğer etkenler de dikkate alınarak (2) denklemi logaritmik formda aşağıdaki gibi yazılabilir.

$$
n e r_{t}=p_{t}-p_{t}^{*}+d_{t}
$$

Burada, $n e r_{t}$ nominal döviz kuru, $p_{t}$ yurt içi fiyat endeksi, $p_{t}^{*}$ yurt dışı fiyat düzeyi ve $d_{t}$ diğer faktörlerin etkileri (örneğin taşıma maliyetleri) nedeniyle ortaya çıkan sapmaları gösteren terimdir. Kullanılan değişkenlerin tamamı logaritmik formdadır. Reel döviz kurundaki dalgalanmalara ilişkin sapmalar ve bu sapmaların neden olduğu ilişki aşağıdaki gibi yazılabilir.

$$
r e r_{t}=n e r_{t}-p_{t}+p_{t}^{*}
$$

$\mathrm{Bu}$ denklemde, rer $_{t}$ reel döviz kurunu tanımlamaktadır. Bu denkleme göre reel döviz kuru, nominal döviz kuru ile yurt dışı fiyat endeksinin toplamından yurt içi fiyat endeksinin çıkarılması ile hesaplanmaktadır. (4) numaralı denklemde yer alan reel döviz 
kurunun durağan süreç olmasi ${ }^{1}$, ilgili ekonomide SAGP hipotezinin geçerli olduğunu göstermektedir. SAGP hipotezinin geçerli olup olmadığını araştırmak için literatürde sıklıkla kullanılan birim kök testi standart ADF testidir. Bu test;

$$
\Delta r e r_{t}=\alpha r e r_{t-1}+x_{t}^{\prime} \delta+\sum_{i=1}^{p} \beta_{i} \Delta r e r_{t-i}+\varepsilon_{t}
$$

Biçimindedir. Burada, $x_{t}^{\prime}$, sabit terim ya da sabit terim ve trend terimini içeren opsiyonel açıklayıcı değişkenler vektörüdür. $\alpha, \delta, \beta_{i}$ tahmin edilen parametrelerdir $\varepsilon_{t}$ ise ak gürültülü (White-noise) hata terimidir. Bu denklemde birim kök için oluşturulacak hipotez testleri;

$$
\begin{aligned}
& H_{0}: \alpha=0 \\
& H_{1}: \alpha<0
\end{aligned}
$$

Şeklindedir. Boş hipotezin reddedilmesi serinin durağan bir süreç olduğunu, boş hipotezin reddedilememesi ise serinin durağan olmadığını göstermektedir. Burada boş hipotezin reddedilmesi SAGP hipotezinin uzun dönemde geçerli olduğunu ortaya koymaktadır.

Literatürde, SAGP hipotezinin geçerli olup olmadığının test edilmesinde kullanılan standart ADF testi sonuçları ile ülkelerde gözlenen ekonomik durum arasında bir uyumsuzluk olduğu ve bu uyumsuzluğun ADF testinin yanlış sonuçlar vermesinden kaynaklandığı şeklinde yaygın bir kanı oluşmuştur (Telatar ve Hasanov, 2009). Özellikle küçük örneklem durumunda ve doğrusal olmayan süreçlerde ADF testinin anlamlılık gücünün düşük kaldığı görülmektedir. Bu nedenle bazı araştırmacılar panel birim kök testlerine yönelirken bazıları da doğrusal olmayan zaman serisi tekniğine dayanan birim kök testlerine yönelmişlerdir. Buradan hareketle çalışmada, hem küçük örneklemlerde daha başarılı sonuç veren ve hem de ele alınan reel döviz kuru serilerinde ortaya çıkan yapısal kırılmaları simetrik ve asimetrik boyutları ile ele alan Kapetanios, Snell, Shin (2003) (KSS) tarafından geliştirilen birim kök testi ile Sollis (2009) tarafından geliştirilen birim kök

I SAGP hipotezinin geçerliliğinin test edilmesinde birim kök testleri ve eş-bütünleşme yöntemi yaygın olarak kullanılmaktadır. Birim kök testleri daha çok reel döviz kuru serileri ele alındığında kullanılır. eş-bütünleşme yöntemi ise, nominal kur, yurtiçi fiyat düzeyi ve yurtdışı fiyat düzeyine ait seriler dikkate alındı̆̆ında kullanilır. Sadoveanu ve Ghiba (2012)'ye göre birim kök testleri SAGP'nin zaylf formda geçerliliğini araştırırken eşbütünleşme yöntemi güçlü formu ele almaktadır. 
testleri kullanılmaktadır. $\mathrm{Bu}$ noktada sözü edilen test prosedürleri aşağıdaki gibi açıklanabilir.

Kapetanios ve diğ. (2003) aşağıdaki ESTAR (üstel yumuşak geçişli otoregresif) modelinden hareket etmektedir.

$$
\Delta \operatorname{rer}_{t}=\operatorname{\gamma rer}_{t-1}\left[1-\exp \left(-\operatorname{\theta rer}_{t-1}^{2}\right]+\sum_{i=1}^{p} \beta_{i} \Delta \operatorname{rer}_{t-i}+\omega_{t}\right.
$$

Sıfır ile bir arasında sınırlanan ve orijin etrafında U-biçimli olan üstel geçiş fonksiyonu $F\left(\theta\right.$, rer $\left._{t-1}\right)=1-\exp \left(-\theta \operatorname{rer}_{t-1}^{2}\right)$ 'dir. $\theta$, geçiş fonksiyonunun eğim parametresi olup, fonksiyonun ekstrem noktalarına karşılık gelen iki rejim arasındaki geçiş hızını belirlemektedir. Serinin global durağanlığı $H_{0}: \theta=0$ boşluk hipotezine karşılık $H_{1}: \theta>0$ hipotezi altında test edilir. Ancak boş hipotez altında $\gamma$ parametresi belirlenemediği için bu test kullanışlı olmamaktadır. Bu problemi giderip $t$-tipi bir test istatistiği geliştirmek için Kapetanios ve diğ. (2003) geçiş fonksiyonunun $\theta=0$ etrafında birinci sıra Taylor açılımını uygulamışlar ve aşağıdaki yardımcı regresyona ulaşmışlardır.

$$
\Delta r e r_{t}=\delta r e r_{t-1}^{3}+\sum_{i=1}^{p} \beta_{i} \Delta r e r_{t-i}+u_{t}
$$

Burada, $u_{t}$ hem Taylor açılımından kaynaklanan hata terimlerini ve hem de orijinal hata terimi $\omega_{t}$ 'den kaynaklanan şokları kapsamaktadır. Yardımcı regresyon $H_{0}: \delta=0$ boşluk hipotezine karşılık $H_{1}: \delta<0$ hipotezi altında test edilir. Kritik değerler Kapetanios ve diğ. (2003)'ten hareketle elde edilmektedir. (8) denklemindeki $\Delta r e r_{t}$ reel döviz kuru serisinin ortalamadan çıkarılmış (de-meaned) seriler olduğu kabul edilmektedir. Bu serilerin durağan olması aynı zamanda serinin uzun dönemde ortalamaya dönme eğiliminde olduğunu göstermesi bakımından da önemlidir.

Öte yandan Sollis (2009), ESTAR sürecine dayanarak asimetrik etkileri dikkate alan ve böylece serinin orijin etrafında simetrik olması gerektiği kısıtını koyan Kapetanios ve diğ. (2003)'nin yapmış olduğu varsayımı yumuşatarak yeni bir test prosedürü ileri sürmüştür. Bu testin en önemli avantaj1, hem simetrik ve hem de asimetrik doğrusal olmayan etkileri dikkate almasıdır (Chang ve diğ, 2012). Sollis (2009) tarafindan geliştirilen AESTAR (Asimetrik üstel yumuşak geçişli otoregresif) modeli aşağıdaki gibi açıklanabilir. 


$$
\Delta r e r_{t}=G_{t}\left(\gamma_{1}, \operatorname{rer}_{t-1}\right)\left\{S_{t}\left(\gamma_{2}, \operatorname{rer}_{t-1}\right) \rho_{1}+\left(1-S_{t}\left(\gamma_{2}, \text { rer }_{t-1}\right)\right) \rho_{2}\right\} r e r_{t-1}+\sum_{i=1}^{p} \beta_{i} \Delta r e r_{t-i}+\psi_{t}
$$

$$
\text { Burada; } \quad G_{t}\left(\gamma_{1}, \text { rer }_{t-1}\right)=1-\exp \left(-\gamma_{1}\left(\text { rer }_{t-1}^{2}\right)\right) \quad \gamma_{1} \geq 0 \quad \text { ve }
$$

$S_{t}\left(\gamma_{2}, \operatorname{rer}_{t-1}\right)=\left[1+\exp \left(-\gamma_{2} \text { rer }_{t-1}\right)\right]^{-1} \quad \lambda_{2} \geq 0$ şeklinde tanımlanmaktadır. Böylece Sollis (2009) genişletilmiş ESTAR sürecini tanımlarken simetrik ve asimetrik etkileri ortaya koymak için lojistik fonksiyonu da modele dâhil etmektedir. (9) numaralı denkleme göre birim kök, simetrik veya asimetrik etkileri dikkate alan global olarak merkez rejim etrafinda ESTAR sürecindeki doğrusal olmayan etkileri içeren $H_{0}: \gamma_{1}=0$ boşluk hipotezi ile sınanır. Ancak bu boşluk hipotezi altında, $\rho_{1}, \rho_{2}$, ve $\gamma_{2}$ parametreleri belirlenememektedir. Bu nedenle Kapetanios ve diğ.(2003)'ten hareketle üstel fonksiyon orijinal modelde $\gamma=0$ etrafinda birinci sıra Taylor açılımına tabi tutulabilir. Ancak bu yaklaşım belirlenemeyen parametreler ile ilgili problemi tamamen ortadan kaldıramamaktadır. Sollis (2009)'un önerisi, lojistik fonksiyonu dikkate alan Taylor açılımını kullanmaktadır. Buradan hareketle elde edilecek model aşağıdaki gibidir.

$$
\Delta r e r_{t}=a\left(\rho_{2}^{*}-\rho_{1}^{*}\right) \gamma_{1} \gamma_{2} r e r_{t-1}^{4}+\rho_{2}^{*} \gamma_{1} \operatorname{rer}_{t-1}^{3}+v_{t}
$$

Burada, $a=1 / 4$ olarak alınırsa (10) denklemi;

$$
\Delta r e r_{t}=\phi_{1} r e r_{t-1}^{3}+\phi_{2} \operatorname{rer}_{t-1}^{4}+v_{t}
$$

Olarak yaz1labilir. Burada; $\phi_{1}=\rho_{2}^{*} \gamma_{1}$ ve $\phi_{2}=a\left(\rho_{2}^{*} \rho_{1}^{*}\right) \gamma_{1} \gamma_{2}$ 'dir. Tahmin edilecek yardımcı regresyon denklemi (11)'in düzeltici terimi de içeren biçimi olarak aşağıdaki gibi yazılabilir.

$$
\Delta r e r_{t}=\phi_{1} r e r_{t-1}^{3}+\phi_{2} r e r_{t-1}^{4}+\sum_{i=1}^{p} \beta_{i} \Delta r e r_{t-i}+v_{t}
$$

Burada test edilecek boş hipotez $H_{0}: \phi_{1}=\phi_{2}=0$ 'dır. Test istatistiğine ilişkin kritik F-istatistik değerleri Sollis (2009)'dan elde edilebilmektedir. Dolayısıyla boş hipotezin red edilmesi kullanılan serilerin durağan olduğu sonucunu vermektedir. 


\section{Veri Seti ve Uygulama}

SAGP hipotezinin geçerliliği, doğrusal olmayan zaman serisi tekniklerine dayanan STAR (Yumuşak Geçişli Oto-regresif model) modelinin en önemli testlerinden olan KSS ve AESTAR birim kök testleri ile araştırılmaktadır. Bu amaçla kullanılan örneklem 1970-2013 dönemine ait yıllık reel döviz kuru serileridir. Bu seriler, Almanya, Birleşik Krallık, Finlandiya, Fransa, Belçika, Hollanda, Yunanistan, Lüksemburg, Norveç, İsveç, İsviçre, Yunanistan, Portekiz, İspanya, İtalya, İrlanda, İzlanda, Meksika, Güney Kore, Japonya, Avustralya, Yeni Zellanda, Kanada, Avusturya ve Türkiye'ye aittir. Veriler OECD veri tabanından alınmış ve ulusal para birimi başına ABD doları olarak SAGP cinsinden tanımlanmıştır. Bu ülkelerin seçilme nedeni hem aralarında yoğun bir dış ticaret ilişkisinin olması ve hem de 1970'li yıllardan sonra hemen hemen hepsinin serbest diş ticaret politikası izlemeye başlamalarıdır. Bu ülkelerde 1970 yılından sonra ortaya çıkan konjonktürel şoklar benzerlik göstermektedir. Bretton-Woods sisteminin çökmesi, petrol şoklarının yaşanması, para politikasının fiyat istikrarı sağlama hedefine ulaşmak için daha etkin olarak kullanılmaya başlanması ve sermaye hareketlerinin serbestleşerek küreselleşme sürecinin hızlanması bu döneme denk gelmektedir. Sözü edilen bu konjonkturel şoklar daha çok ele alınan 25 OECD ülkesinde kendini hissettirmiştir.

Tablo: 1

ADF Test Sonuçları

\begin{tabular}{|c|c|c|}
\hline ÜLKE & ADF TESTİ & GECİKME UZUNLUĞU \\
\hline Almanya & -2.5474 & 1 \\
\hline Avusturya & $-2.9516^{*}$ & 0 \\
\hline Avustralya & -0.1975 & 0 \\
\hline Belçika & $-2.8878^{*}$ & 1 \\
\hline Kanada & $-3.8119 * * *$ & 0 \\
\hline Danimarka & $-2.6831 *$ & 2 \\
\hline Finlandiya & $-3.4473 * *$ & 2 \\
\hline Fransa & -2.4240 & 1 \\
\hline Hollanda & 0.0300 & 0 \\
\hline İrlanda & -2.5075 & 1 \\
\hline İzlanda & -0.1954 & 1 \\
\hline İtalya & -2.4613 & 1 \\
\hline İsveç & $-2.7984 *$ & 0 \\
\hline İsviçre & -1.3591 & 1 \\
\hline Japonya & -1.4299 & 7 \\
\hline Güney Kore & -2.1707 & 1 \\
\hline Norveç & -2.5402 & 0 \\
\hline Meksika & -0.3981 & 1 \\
\hline Portekiz & $-3.7117 * * *$ & 0 \\
\hline İspanya & $-2.6829 *$ & 1 \\
\hline Yunanistan & -2.1613 & 2 \\
\hline Türkiye & 0.6260 & 2 \\
\hline Yeni Zelanda & -1.9101 & 0 \\
\hline Lüksemburg & $-3.8881 * * *$ & 0 \\
\hline Birleşik Krallık & $-3.5947 * * *$ & 0 \\
\hline
\end{tabular}

Not: ***ve *** ifadeleri strasıyla $\% 10, \% 5$ ve \%1 anlamlılık düzeylerini göstermektedir. 
Analizde öncelikli olarak standart ADF testi uygulanmakta ardından KSS ve AESTAR testlerine bakılmaktadır. Böylece OECD ülkelerinde SAGP hipotezinin geçerliliği araştırılmaktadır. Literatürde önemli araştırma konularından olan SAGP hipotezi, iktisat politikaları oluşturulurken dikkate alınmaktadır. Hipotezin geçerli olması merkez bankalarının bağımsız para politikası uygulama konusunda elini güçlendirmektedir. Ayrıca SAGP'nin ülkeler arasında refah karşılaştırması yapılırken kullanımının, uygun olduğunu göstermektedir.

Tablo: 1 ADF test sonuçlarını göstermektedir. Bu tabloya göre 1970-2013 döneminde SAGP hipotezi \%1 anlamlılık düzeyinde, Lüksemburg, Portekiz, Birleşik Krallık ve Kanada için geçerlidir. \%5 anlamlılık düzeyinde, Avustralya ve Finlandiya'da geçerlidir. Son olarak \%10 anlamlılık düzeyinde ise, Belçika, Danimarka, İspanya ve İsveç’te geçerlidir. Ülkelerin reel döviz kuru serilerine ait gecikme uzunlukları AIC (Akaike Bilgi Kriteri)'ye göre belirlenmektedir.

Tablo: 2

KSS Test Sonuçları

\begin{tabular}{|l|c|c|}
\hline ÜLKE & KSS TESTI & GECIKME UZUNLUĞU \\
\hline Almanya & $\mathbf{- 4 . 3 8 4 7 * * *}$ & $\mathbf{0}$ \\
\hline Avusturya & -2.8910 & $\mathbf{3}$ \\
\hline Avustralya & $-0,9083$ & 1 \\
\hline Belçika & -2.2037 & 7 \\
\hline Kanada & 1.9323 & 5 \\
\hline Danimarka & -0.6607 & 6 \\
\hline Finlandiya & -0.3645 & 0 \\
\hline Fransa & -0.5866 & 4 \\
\hline Hollanda & -0.0980 & 4 \\
\hline İrlanda & -0.8005 & 4 \\
\hline İzlanda & -0.0107 & 3 \\
\hline İtalya & -0.7002 & 6 \\
\hline İsveç & -0.4983 & 3 \\
\hline İsviçre & $\mathbf{- 3 . 9 5 8 0 * * *}$ & 4 \\
\hline Japonya & $\mathbf{- 7 . 0 5 5 4 * * *}$ & 0 \\
\hline Güney Kore & 0.2539 & 4 \\
\hline Norveç & 0.1509 & 3 \\
\hline Meksika & -0.7251 & 3 \\
\hline Portekiz & -1.1801 & 4 \\
\hline İspanya & -0.8628 & 4 \\
\hline Yunanistan & -1.8901 & 3 \\
\hline Türkiye & -0.1801 & 4 \\
\hline Yeni Zelanda & -0.0980 & 4 \\
\hline Lüksemburg & -1.2981 & 1 \\
\hline Birleşik Krallı & 0.7684 & \\
\hline
\end{tabular}

Not: *,**ve *** ifadeleri straslyla \%10, \%5 ve \%1 anlamlllık düzeylerini göstermektedir. Test istatistiği için kritik değerler Kapetanios ve diğ. (2003)'ten alınmaktadır. 
Tablo: 2, Kapetanios ve diğg. (2003) tarafından geliştirilen KSS test istatistiği sonuçlarını göstermektedir. Literatürde oluşan yaygın kanıya uygun olarak burada SAGP hipotezi doğrusal olmayan zaman serisi tekniklerine dayanan birim kök testi ile araştırılmaktadır. Tabloya göre, \%1 anlamlılık düzeyinde Almanya, Japonya ve İsviçre için SAGP hipotezi geçerlidir. $\% 5$ ve $\% 10$ anlamlılık düzeylerinde ise herhangi bir ülkede SAGP hipotezi geçerli değildir. Gecikme uzunluğu AIC'ye göre belirlenmektedir.

Tablo: 3, Sollis (2009) tarafından geliştirilen AESTAR (Asimetrik üstel yumuşak geçişli oto-regresif model) test sonuçlarını göstermektedir. Bu tabloya göre SAGP hipotezi 25 OECD ülkesinden 20 tanesinde geçerlidir. SAGP hipotezi \%1 anlamlılık düzeyinde; Finlandiya, Kanada, Avustralya, Birleşik Krallık, Yeni Zelanda, Almanya, İzlanda, Japonya, Güney Kore, Lüksemburg, İsveç, ve İsviçre'de geçerlidir. \%5 anlamlılık düzeyinde SAGP hipotezi; İrlanda, İtalya, İspanya, Türkiye, Yunanistan, Avusturya, Danimarka ve Norveç’te geçerlidir. \%10 anlamlılık düzeyinde SAGP hipotezi herhangi bir ülkede geçerli değildir.

Tablo: 3

\section{AESTAR Test Sonuçları}

\begin{tabular}{|c|c|c|}
\hline ÜLKE & AESTAR TESTI & GECİKME UZUNLUĞU \\
\hline Almanya & $10.6593 * * *$ & 0 \\
\hline Avusturya & $5.9774 * *$ & 4 \\
\hline Avustralya & $14.8116 * * *$ & 0 \\
\hline Belçika & 2.0297 & 0 \\
\hline Kanada & $12.7509 * * *$ & 2 \\
\hline Danimarka & $6.5649 * *$ & 0 \\
\hline Finlandiya & $13.6292 * * *$ & 0 \\
\hline Fransa & 2.7855 & 0 \\
\hline Hollanda & 3.9930 & 5 \\
\hline İrlanda & $5.2918 * *$ & 0 \\
\hline İzlanda & $14.1044 * * *$ & 0 \\
\hline İtalya & $5.3726 * *$ & 1 \\
\hline İsveç & $8.4776 * * *$ & 1 \\
\hline İsviçre & $9.7426 * * *$ & 3 \\
\hline Japonya & $7.4568 * * *$ & 5 \\
\hline Güney Kore & $15.2817 * * *$ & 0 \\
\hline Norveç & $5.2358 * *$ & 0 \\
\hline Meksika & 0.8514 & 3 \\
\hline Portekiz & 2.7863 & 0 \\
\hline İspanya & $5.6704 * *$ & 1 \\
\hline Yunanistan & $6.2791 * *$ & 1 \\
\hline Türkiye & $6.2286 * *$ & 0 \\
\hline Yeni Zelanda & $14.1771 * * *$ & 1 \\
\hline Lüksemburg & $7.2675 * * *$ & 2 \\
\hline Birleşik Krallık & $15.8165 * * *$ & 0 \\
\hline
\end{tabular}

Not: *** 5 ve \%1 anlamllllk düzeylerini göstermektedir. Test istatistiği için kritik değerler Sollis(2009)'dan alınmaktadir. 
Sonuç olarak; SAGP hipotezi, Belçika, Fransa, Meksika, Portekiz ve Hollanda için geçerli değildir. Bu ülkelerde merkez bankası bağımsız para politikası izleme olanağına sahip değildir. Fransa, Belçika, Hollanda ve Portekiz'de merkez bankalarının enflasyon hedeflemesi rejimini henüz benimsememiş olmaları ayrıca ilginçtir. Çünkü döviz kurlarındaki dalgalanmaların yaratacağı şoklar, kalıcı hasarlara neden olabilmektedir. Reel döviz kuru serileri ortalamaya dönme eğilimi göstermemektedir. Ayrıca bu ülkeler için refah karşılaştırması yapılırken SAGP'nin kullanımı da uygun değildir. Diğer ülkelerde ise seriler durağandır ve ortalamaya dönme eğilimi göstermektedir. Durağanlık özelliğinin söz konusu olduğu ülkelerde merkez bankaları döviz kuru istikrarını sağlama baskısı altında değildirler. Bu nedenle bağımsız para politikası uygulama olană̆ına sahiptirler.

\section{Sonuç}

25 OECD ülkesi için 1970-2013 dönemine ait yıllık reel döviz kuru serileri kullanılarak SAGP hipotezinin doğrusal olmayan zaman serisi tekniğine dayanan KSS ve AESTAR birim kök testleri kullanılarak incelendiği bu çalışmadan elde edilen bulgular şu şekilde özetlenebilir.

Literatürdeki yaygın kanı, makroekonomik verilere ait zaman serilerinin durağan olmadığ ve bu serilerin durağanlıkları araştırılırken doğrusal olmayan birim kök testlerinin kullanımının uygun olacağı biçimindedir. Bu düşünceden hareketle, reel döviz kuru serileri KSS ve AESTAR birim kök testleri ile durağanlık sınamasına tabi tutulmaktadır. SAGP hipotezinin geçerliliği, ülkelerde iktisat politikalarının oluşturulmasında_önemli bir başlangıç noktasıdır. Çünkü günümüz dünyasında ülkeler arasında ticari engeller hızla kalkmakta, sermaye hareketleri serbestleşmekte ve dış ticaret hacminde önemli artışlar yaşanmaktadır. Dolayısıyla döviz kurlarının istikrarsız olması iktisat politikalarına yön verenlerin elini kolunu bağlamaktadır. Politika yapıcılar enerjilerinin önemli bir kısmını döviz kuru istikrarına harcamakta ve ası makroekonomik problemleri gözden kaçırabilmektedirler.

1970'li y1llardan sonra para politikasının içselleşmesi ve ekonomilerdeki asıl sorunun fiyat istikrarı olması, kurala dayalı politika anlayışının benimsenmesini zorunlu kılmıştır. Günümüzde Türkiye dâhil birçok ülkede popüler hale gelen enflasyon hedeflemesi rejimi, merkez bankalarının para politikası uygulamalarında bağımsız olmalarını gerektirmektedir. Bu perspektiften bakıldığında SAGP hipotezinin geçerli olması merkez bankalarının politika uygulamalarının başarıya ulaşması açısından hayati derecede önemlidir.

Çalışmadan elde edilen bulgulara göre; KSS testi sadece üç ülkede SAGP hipotezinin geçerliliği lehinde kanıtlar sunarken serilerde simetrik ve asimetrik etkilerin varlığına izin veren AESTAR testi yirmi ülkede SAGP hipotezinin geçerli olduğunu göstermektedir. Geri kalan beş ülkede ise SAGP hipotezi geçerli değildir. Bu noktada, SAGP hipotezinin geçerli olmadı̆̆ı, Fransa, Hollanda, Belçika, Portekiz ve Meksika'da politika 
otoritelerinin iktisat politikalarını oluştururken ve uygularkenki önceliğinin döviz kuru istikrarı olması gerekmektedir.

Sonuç olarak bu çalışma, diğer çalışmalardan doğrusal olmayan zaman serisi tekniğine dayanan ve ele alınan serilerde simetrik ve asimetrik davranışlara vurgu yapan AESTAR yönteminin kullanılması noktasında ayrılmaktadır. Bu durumda makroekonomik değişkenlerin doğrusal olmayan davranışlar sergilemesi halinde durağanlık araştırması yapılırken AESTAR modelinin kullanımı uygun görünmektedir.

\section{Kaynakça}

Alba, J.D. \& D. Papell (2007), "Purchasing Power Parity and Country Characteristics: Evidence from the Panel Data Tests", Journal of Development Economics, 83, 240-251.

Benassy, A. \& V. Duran \& R. Lahreche \& V. Ignon (2005), "Real Equilibrium Exchange Rates: A G20 Panel Co-integration Approach”, Thema working paper, 2005.

Breitung, J. \& B. Candelon (2005), "Purchasing Power Parity During Currency Crises: A Panel Unit Root Test under Structural Breaks", Review of World Economics, 141(1), 124-140.

Cang, T. \& C. Lee \& P. Chou \& D. Tang (2011), "Revisiting Long-run Purchasing Power Parity with Asymetric Adjustment for G-7 Countries", Japan and the World Economy, 23, 259264.

Chang, T. \& C. Lee \& W. Liu (2012), "Non linear adjustment to purchasing power parity for ASEAN countries", Japan and the World Economy, 24(4), 325-331.

Cassel, G. (1918), "Abnormal deviations in international exchanges", The Economic Journal, 28, 413-415.

Çağlayan, E. \& N. Saçaklı (2006), "Satın Alma Gücü Paritesinin Geçerliliğinin Sıfır Frekansta Spektrum Tahmincisine Dayanan Birim Kök Testleri ile İncelenmesi”, Atatürk Üniversitesi İBF Dergisi, 20, 121-137.

Doğanlar, M. (2006), "Long-Run Validity of Purchasing Power Parity and Co-integration analysis for Central Asian Countries", Applied Economics Letters, 13, 457-461.

Gözgör, G. (2013), "Purchasing Power Parity Hypothesis Amongthe Main Trade Partners of Turkey", Economics Bulletin, 31, 1432-1438.

Güloğlu, B. \& S. İspir \& D. Onat (2011), "Testing the validity of quasi PPP hypothesis: Evidence from a recent panel unit root test with structural breaks", Applied economics letters, 18, $1817-1822$.

Holmes, M.J. \& J. Otero \& J. Panagiotidis (2012), "PPP in OECD Countries: An Analysis of Real Exchange Rate Stationary Cross-Sectional Dependancy and Structural Breaks", Open Economics Review, 23(5), 767-783.

Kalyoncu, H. \& K. Kalyoncu (2008), "Purchasing power parity in OECD countries: Evidence from panel unit root", Economic Modelling, 25(3): 440-445.

Kapetanios, G. \& Y. Shin \& A. Snell (2003), "Testing for a unit root in the non-linear STAR framework", Journal of Econometrics, 16, 359-379.

Karoglou, M. \& B. Morley (2012), "Purchasing Power Parity and Structural instability in the US/UK Exchange rate", Int. Fin. Markets, Int. and Money, 22, 958-972. 
Korkmaz, T. \& E.İ. Çevik \& N.K. Çevik (2013), "Satın Alma Gücü Paritesinin Azerbaycan, Kazakistan ve Kırgızistan için Geçerliliğinin Test Edilmesi: Birim Kök ve Eşbütünleşme Analizi”, Bilig, (64), 259-284.

Liu, S. \& D. Zhang \& T. Chang (2012), "Purchasing power parity non linear threshold unit root test for transition countries", Applied Economics Letters, 19, 1781-1785.

Nelson, C.R. \& C.R. Plosser (1982), "Trends and Random Walks in Macroeconomic Time Series: Some Evidence and Implications", Journal of Monetary Economics, 10 (2), 139-162.

Payne, J. \& J. Lee \& R. Hofler (2005), "Purchasing power parity: evidence from a transition economy", Journal of Policy Modelling, 27, 665-672.

Rogoff, K. (1996), “The Purchasing Parity Puzzle", Journal of Economic Literature, 34, 647-668.

Roos, F. (1981), "Purchasing Power Parity Theory and the Monetary Approach to the Balance of Payments", De Economist, 129(1), 41-57.

Sadoveanu, D. \& N. Ghiba (2012), "Purchasing power parity: Evidence from four CEE Countries", Journal of Academic Research in Econometrics, 4(1), 80-90.

Sarno, L. \& M.P. Taylor (2002), "Real Exchange Rate Behaviour in High Inflation Countries: Empirical evidence from Turkey, 1980-1997”, Applied Economics Letters, 7, 289-291.

Sayyan, H. (2005), “Satın Alma Gücü Paritesi: Vektör Hata Giderme Modeli Yaklaşımı”, İktisat, Işletme ve Finans, Temmuz, 96-104.

Snaith, S. (2012), "The PPP Debate: Multiple breaks and cross-sectional dependence", Economics Letters, 115, 342-344.

Sollis, R. (2009), “A Simple Unit Root Test Against Asymetric STAR Nonlinearity With An Application to Real Exchange Rates in Nordic Countries", Economic Modelling, 26, 118125.

Şak, N. (2006), “OECD Ülkelerinde Satın Alma Gücü Paritesinin Geçerliliğinin Panel Eşbütünleşme Yaklaşımı ile İncelenmesi”, Yayımlanmamış Yüksek Lisans Tezi, Marmara Üniversitesi Sosyal Bilimler Enstitüsü.

Taylor, A. (2002), “A Century of Purchasing-Power Parity”, Review of Economics and Statistics, 84, 139-150.

Taylor, M.P. (2006), "Real Exchange Rates and Purdhasing Power Parity: Mean reversion in economic thought", Applied Economics, 16, 1-17.

Telatar, E. \& M. Hasanov (2009), "Purchasing power parityin transition economies: Evidence from the Commonwealth of Independent States", Post-Communist Economies, 21(2), 157-173.

Wallace, F.H. \& G.L. Shelley (2006), “An Alternative Test of Purchasing Power Parity”, Economics Letters, 92, 177-183.

Yıldırım, K. \& Z. Yıldırım (2012), "Reel efektif döviz kuru üzerinde kırılmalı birim kök testi ile Türkiye için satın alma gücü paritesi hipotezinin geçerliliğinin sınanması", Marmara Üniversitesi IIIBF Dergisi, 33(2), 221-238.

Yıldırım, K. \& M. Mercan \& F.S. Kostakoğlu (2013), "Satın alma gücü paritesinin test edilmesi: Zaman serisi ve panel veri analizi”, Eskişehir Osmangazi Üniversitesi IİBF Dergisi, 8(3), 75-95. 
Reşat CEYLAN \& Hakan ULUCAN

210 